\title{
Astigmatic correction of simultaneous femtosecond laser-assisted cataract surgery (FLACS) with intrastromal arcuate keratotomy (ISAK) versus Toric intraocular Lens Impantation with conventional phacoemulsification
}

Hye Ji Kwon, Hun Lee, Jin Ah. Lee, Jae Yong Kim and Hungwon Tchah ${ }^{*}$ i]

\begin{abstract}
Background: To compare the efficacies in astigmatic correction of simultaneous femtosecond laser-assisted cataract surgery (FLACS) with intrastromal arcuate keratotomy (ISAK) versus toric intraocular lens (IOL) implantation with conventional phacoemulsification in moderate astigmatism.

Methods: A retrospective chart review was conducted for patients who had undergone cataract surgery by one surgeon. We identified patients with preoperative corneal astigmatism from +0.75 to +2.00 diopters (D) who had undergone astigmatic correction with FLACS with ISAK or toric IOL implantation with conventional phacoemulsification. We measured the visual acuity, intraocular pressure, automated keratometer, manifest refraction, and topography preoperatively and 1-day, 1-month, 3-month, and 6-month postoperatively. The vector analysis of refractive astigmatism was performed.

Results: Of a total of 48 eyes of 48 patients, 27 eyes of 27 patients had FLACS with ISAK (AK group), and 21 eyes of 21 patients had conventional cataract surgery with toric IOL implantation (toric IOL group). Refractive astigmatism was significantly decreased in both groups. The mean preoperative and 6-month postoperative refractive astigmatism were $1.85 \pm 1.07$ and $0.99 \pm 0.51 \mathrm{D}$, respectively, in the AK group $(P=0.028)$, and $1.84 \pm 0.81$ and $0.68 \pm$ $0.21 \mathrm{D}$, respectively, in the toric $\mathrm{IOL}$ group $(P<0.001)$. There was no significant difference in refractive astigmatism between the two groups at 6-month postoperatively $(0.99 \pm 0.51$ vs $0.68 \pm 0.21 \mathrm{D}, P=0.057)$. At 6-month postoperatively, parameters for vector analysis of refractive astigmatism showed no statistical difference between the two groups. Corneal astigmatism was significantly decreased in the AK group. Corneal astigmatism from topography and the automated keratometer were significantly lower in the AK group 6-month postoperatively compared to toric IOL group ( $0.94 \pm 0.40$ vs. $1.53 \pm 0.46 \mathrm{D}, P=0.018$ for topography; and $0.98 \pm 0.69$ vs. $1.37 \pm 0.41$
\end{abstract}

\footnotetext{
* Correspondence: hwtchah@amc.seoul.kr

Department of Ophthalmology, Asan Medical Center, University of Ulsan College of Medicine, 88, Olympic-Ro 43-Gil, Songpa-Gu, Seoul 05505, South Korea
}

(c) The Author(s). 2021 Open Access This article is licensed under a Creative Commons Attribution 4.0 International License, which permits use, sharing, adaptation, distribution and reproduction in any medium or format, as long as you give appropriate credit to the original author(s) and the source, provide a link to the Creative Commons licence, and indicate if changes were made. The images or other third party material in this article are included in the article's Creative Commons licence, unless indicated otherwise in a credit line to the material. If material is not included in the article's Creative Commons licence and your intended use is not permitted by statutory regulation or exceeds the permitted use, you will need to obtain permission directly from the copyright holder. To view a copy of this licence, visit http://creativecommons.org/licenses/by/4.0/ The Creative Commons Public Domain Dedication waiver (http://creativecommons.org/publicdomain/zero/1.0/) applies to the data made available in this article, unless otherwise stated in a credit line to the data. 
$D, P=0.032$ for the automated keratometer).

Conclusions: FLACS with ISAK could be an effective procedure for reducing astigmatism as well as toric IOL implantation in cataract surgery.

Keywords: Femtosecond laser-assisted cataract surgery, Femtosecond laser-assisted intrastromal arcuate keratotomy, Toric intraocular lens implantation, Astigmatism, Cataract surgery

\section{Introduction}

A significant number of patients undergoing cataract surgery tend to have a varying degree of corneal astigmatism [1, 2]. Approximately, a third of cataract patients have more than 1.25 diopters (D) of preexisting corneal astigmatism, whereas approximately $10 \%$ have $2.00 \mathrm{D}$ or higher [1-6]. The reduction of refractive astigmatism after cataract surgery can result in a significant improvement in visual quality, but residual astigmatism decrease visual acuity and quality of vision $[7,8]$. Postoperative astigmatism is an important cause for the lack of achieving emmetropia even after routine cataract surgery $[9,10]$.

Over the past decade, various approaches, including limbal relaxing incisions, corneal incision on the steep axis, astigmatic refractive keratectomy, and toric intraocular lens (IOL) implantation, have been employed to reduce preexisting astigmatism during cataract surgery [10-12]. However, limbal relaxing incisions have limitations that include restricted predictability, induced irregular astigmatism, induced ocular aberrations, and abnormal wound healing $[11,12]$. Excimer laser procedures after cataract surgery are useful for eliminating residual astigmatism but are rarely used because of availability and ocular surface problems following excimer laser treatment [13]. Toric IOL implantation during cataract surgery allows better management of astigmatism, leading to better uncorrected visual acuity $[14,15]$.

Femtosecond laser-assisted intrastromal arcuate keratotomy (ISAK), demonstrating higher precision, safety, and reproducibility in reducing refractive astigmatism, has been suggested as an alternative to these surgical techniques $[16,17]$. Along with the introduction of femtosecond laser-assisted cataract surgery (FLACS), cataract surgeons could perform femtosecond laser-assisted ISAK during FLACS to reduce corneal astigmatism [1822]. Our previous study observed no difference in postoperative astigmatism correction between femtosecond laser-assisted trans-epithelial arcuate keratotomy (AK) after cataract surgery for residual astigmatism and conventional cataract surgery with toric IOL implantation [19]. The aim of the present study was to compare the efficacies in astigmatic correction of simultaneous FLACS with ISAK versus toric IOL implantation with conventional phacoemulsification in patients with moderate astigmatism.

\section{Methods}

We conducted this retrospective study with the approval of the Institutional Review Board of the Asan Medical Center and the University of Ulsan College of Medicine, Seoul, South Korea (2019-1244). The study adhered to the tenets of the Declaration of Helsinki and followed good clinical practice. All patients were informed of risks and benefits of the surgery and provided written consent for surgery.

A retrospective chart review was conducted for patients who had undergone cataract surgery by one surgeon $(\mathrm{HT})$ at the cataract and refractive clinic of the Asan Medical Center. We identified those who had undergone astigmatic correction through FLACS with ISAK or toric IOL implantation with conventional phacoemulsification. Medical records of those who had completed all follow-up visits for 6 months (1-, 3-, and 6-month postoperatively) were reviewed. Patients who met the following inclusion criteria were included: age above 18 years, the presence of preexisting corneal astigmatism ranging from +0.75 to $+2.00 \mathrm{D}$, and agreement of FLACS with ISAK or toric IOL implantation during cataract surgery. Only one eye per patient was included. For patients who had undergone cataract surgeries in both eyes, the first eye was included. Patients were excluded from the analyses if they had any optical opacities or pathologies on slit-lamp examination, previous corneal surgeries, ocular trauma, intraocular surgery, severe dry eye, corneal disease, ocular infection, or collagen vascular/autoimmune diseases. Among all the finally included patients, those who had undergone FLACS with ISAK were categorized under the AK group and those who had undergone cataract surgery with implantation of toric IOL were categorized under the toric IOL group.

All surgeries were performed by one surgeon using topical anesthesia ( $0.5 \%$ proparacaine hydrochloride). Cataract surgeries were performed with phacoemulsification and implantation of a foldable IOL with $2.2 \mathrm{~mm}$ limbal incision. The incisions were located at the steep axis of cornea measured by automated keratometer. All non-toric or toric IOLs were injected into the capsular bag. Main incisions were sealed with anterior stromal hydration without corneal sutures. Topical antibiotics and steroid eyedrops were used for 1-month after surgery. 
In the AK group, all patients underwent cataract surgery using the Catalys femtosecond laser platform (Abbott Medical Optics, Inc., Santa Ana CA, USA). Horizontal limbal marker was done in sitting position prior to the laser to avoid cyclotorsion. After the patient lies supine, a suction ring with vacuum was aligned with corneal marks, and a safe distance for the docking interface was controlled with a joystick by the surgeon. After surgical site and depth was confirmed using the incorporated optical coherence tomography cross section, anterior capsulotomy and lens fragmentation were performed, followed by the ISAK. The programmed anterior capsulotomy size was $4.8 \mathrm{~mm}$ in diameter. Crystalline lens fragmentation was done using a standard template with a pattern described as "lens softening: quadrants" in the system.

ISAK nomogram of paired symmetric (same length) incisions centered on the steep corneal axis was done, with $8.0 \mathrm{~mm}$ in diameter and central $60 \%$ of total corneal thickness in depth remaining upper 20\% and lower 20\% without penetration. The arc length was determined by ISAK nomogram calculator v3, which has been provided on the website (http://www.femtoemulsification.com, v3.4, accessed November 1, 2018). The steep axis value to be entered in the calculator was decided from the automated keratometer. The length was proportional to preoperative corneal cylindrical power and was adjusted by the age and type of astigmatism, i.e., against-the-rule, with-the-rule, or oblique astigmatism. Foldable aspheric IOL (TECNIS 1-piece ZCB00 or PCB00 IOL; Abbot Medical Optics, Inc.) was implanted in patients of the AK group. The primary effectiveness target in femtosecond laser-assisted ISAK was refractive astigmatism for comparison with the toric IOL group. Corneal astigmatism was also evaluated.

In the toric IOL group, horizontal corneal-limbal marks using a sterile pen was made in each patient, while each was in a sitting position to avoid cyclotorsion. After a patient lied in a supine position in the operating room with aseptic drape, intraoperative markings were made under a surgical microscope with guidance from preoperative horizontal markings. After phacoemulsification, toric IOL (TECNIS Toric IOL; Abbott Medical Optics, Inc.) was implanted. The primary effectiveness target of toric IOL implantation was refractive astigmatism. The appropriate cylindrical power and axis placement of the toric IOL to be implanted were determined with the Barrett toric calculator (http://ascrs.org/tools/barrett-toric-calculator, accessed November 1, 2018). The IOL alignment and steep meridian value to be entered in the calculator were determined from the automated keratometer. After the implantation of IOL, IOL alignment and axis were re-checked.
The preoperative and postoperative (1-day, 1-month, 3-month, and 6-month) ophthalmic examinations included uncorrected distance visual acuity (UDVA) and corrected distance visual acuity (CDVA), autorefraction, manifest refraction, intraocular pressure measurements (non-contact tonometer; NT-530, NCT Nidek Co. Ltd., Aichi, Japan), dilated fundus examinations, and slit-lamp examinations (Haag-Streit, Gartenstadtstrasse, Köniz, Switzerland). Corneal astigmatism was measured by corneal topographies with the Orbscan (Bausch \& Lomb, Rochester, NY, USA) and automated keratometer (KR8800, Topcon Europe Medical BV). Additionally, for measuring ocular biometry such as axial length and anterior chamber depth, IOL Master 500 (Carl Zeiss Meditec, Oberkochen, Germany) was used.

Vector analysis of refractive astigmatism is based on the definitions and formulas given by Eydelman MB [23, $24]$. We analyzed the intended refractive correction, surgically induced refractive correction, error ratio, correction ratio, error of magnitude, and error of angle. The intended refractive correction is the vector difference between the preoperative and the target postoperative cylinder vector. Assuming that target refractive state is emmetropia, it is equal to the preoperative astigmatism. The surgically induced refractive correction is defined as an amount and axis of astigmatism change achieved by surgery. The error ratio is the proportion of the intended correction that was not successfully corrected. The correction ratio is the ratio of the achieved correction magnitude to the targeted correction magnitude; whereas the error of magnitude is the difference in magnitudes between the surgically induced refractive correction and intended refractive correction. Finally, the error of angle is the angular difference between the achieved correction and the intended correction. Double-angle plots of preoperative corneal astigmatism and postoperative refractive astigmatism (3-month and 6-month) are drawn. The double-angle plot tool used in this paper is available on the American Society of Cataract and Refractive Surgery website (http://ascrs.org/tools/astigmatism-doubleangle-plot-tool, accessed November 1, 2018) [25].

The Mann-Whitney $U$ test, Wilcoxon signed-rank test, and Chi-square test were used for statistical analyses using the SPSS software version 21.0 (SPSS, Inc., Chicago, IL, USA). Differences were considered to be statistically significant for $P$ values less than 0.05 . Data from automated keratometer and topography were analyzed using vector analysis.

\section{Results}

A total of 48 patients were identified in the study period. Of the 48 eyes of 48 patients, 27 eyes of 27 patients had undergone FLACS with ISAK, and 21 eyes of 21 patients had undergone conventional cataract surgery with toric 
IOL implantation. Demographics of the $\mathrm{AK}$ and toric IOL groups are summarized in Table 1 . There were no significant differences in the mean age, preoperative UDVA, preoperative corneal astigmatism, and refractive astigmatism between the two groups. Preoperative CDVA was different between the two groups. No ocular complications, such as corneal ectasia or epithelial ingrowth, were reported in all cases.

Table 2 demonstrates the results of refractive astigmatism and corneal astigmatism for both $\mathrm{AK}$ and toric IOL group. Significant reduction of refractive astigmatism was observed in both groups at 1-month, 3-month, and 6-month after the surgery, when compared with preoperative refractive astigmatism $(1.85 \pm$ 1.07 preoperatively, $0.96 \pm 0.37$ at 1 -month, $0.76 \pm 0.42$ at 3-month, $0.99 \pm 0.51$ at 6 -month postoperatively, $\boldsymbol{P}=0.001, \boldsymbol{P}<0.001, \boldsymbol{P}=0.028$, respectively, in AK group, and $1.84 \pm 0.81$ preoperatively, $0.63 \pm 0.32$ at 1 month, $0.67 \pm 0.34$ at 3 -month, $0.68 \pm 0.21$ at 6 - month postoperatively, $\boldsymbol{P}=0.001, \boldsymbol{P}=0.001, \boldsymbol{P}=0.001$, respectively, in toric IOL group; Table 2). There was no significant difference of refractive astigmatism between the two groups at 3-month and 6-month after surgery $(0.76 \pm 0.42$ in $\mathrm{AK}$ group vs $0.67 \pm 0.34$ in toric IOL group, $\boldsymbol{P}=0.483$, at 3 -month, and $0.99 \pm$ 0.51 in AK group vs $0.68 \pm 0.21$ in toric IOL group, $\boldsymbol{P}=0.057$, at 6 -month postoperatively; Table 2). Figure 1 shows a box and whisker plot of refractive astigmatism by group and time. The median refractive astigmatism had been significantly corrected postoperatively compared to baseline in both groups. The AK group showed larger interquartile ranges 1 - and 6month postoperatively compared to the toric IOL group. The corneal astigmatism was significantly reduced only in the AK group at 1-month, 3-month, and 6-month after the surgery, when compared with preoperative corneal astigmatism (automated keratometer: $P=0.001,0.009$, and 0.013 at $1-, 3-$, and 6month postoperatively, respectively; topography: $P<$ $0.001, P=0.003, P=0.010$ at $1-, 3-$, and 6-month postoperatively, respectively; Table 2). Between two groups, significant difference of corneal astigmatism at all of each postoperative follow-up period was observed (Table 2).

Table 3 demonstrates the results of vector analysis of refractive astigmatism. There was no significant difference in all vector analysis parameters (surgically induced refractive correction, error ratio, correction ratio, error of magnitude, and error of angle) between the two groups at 1-month, 3-month, and 6-month after surgery (all $\boldsymbol{P}$ values $>0.05$; Table 3 ) except error ratio at 1 -months postoperatively $(0.66 \pm 0.44$ in AK group vs $0.31 \pm 0.21$ in toric IOL group, $\boldsymbol{P}=$ 0.011; Table 3). In the AK group, there was no significant difference between the 1-month, 3-month, and 6-month postoperative vector analysis parameters (all $\boldsymbol{P}$ values $>0.05$; Table 3 ). In the toric IOL group, there were significant differences between 1-month and 3-month and between 1-month and 6-month postoperatively in surgically induced refractive correction, correction ratio, and error of magnitude (1month vs. 3 -month and 1 -month vs. 6 -month, $P=$ 0.006 and 0.009 , respectively, in surgically induced refractive correction; 1-month vs. 3-month and 1month vs. 6 -month, $P=0.004$ and 0.013 , respectively, in the correction ratio; and 1-month vs. 3 -month and 1 -month vs. 6-month, $P=0.006$ and 0.009 , respectively, in the error of magnitude; Table 3 ).

Figures show double-angle plots of preoperative corneal astigmatism and postoperative refractive astigmatism at 3-month and 6-month after surgery in both AK group (Figs. 2 and 3) and toric IOL group (Figs. 4 and

Table 1 Demographics and clinical characteristics of the participants

\begin{tabular}{|c|c|c|c|}
\hline & AK group & toric IOL group & $P^{a}$ \\
\hline Number of eyes $(n)$ & 27 & 21 & \\
\hline Male/Female (\% women) & $9 / 18(66.7)$ & $8 / 13(61.9)$ & 0.732 \\
\hline Right/Left & $18 / 9$ & $10 / 11$ & 0.184 \\
\hline Age (years) & $69.4 \pm 12.1$ (39 to 89$)$ & $67.4 \pm 12.5(41$ to 86$)$ & 0.581 \\
\hline ATR/WTR/Oblique & $15 / 8 / 4$ & $12 / 6 / 3$ & 0.994 \\
\hline Preoperative UDVA (logMAR) & $0.67 \pm 0.442(0.1$ to 2.0$)$ & $0.43 \pm 0.29(0.15$ to 1.3$)$ & 0.077 \\
\hline Preoperative CDVA (logMAR) & $0.43 \pm 0.39$ (0.1 to 2.0$)$ & $0.22 \pm 0.13(0.1$ to 0.6$)$ & 0.038 \\
\hline Corneal astigmatism from topography (D) & $1.49 \pm 0.36(1.3$ to 2.0$)$ & $1.60 \pm 0.47(1.2$ to 2.0$)$ & 0.235 \\
\hline Corneal astigmatism from automated keratometer (D) & $1.44 \pm 0.39(1.0$ to 2.0$)$ & $1.50 \pm 0.37$ (0.87 to 2.0$)$ & 0.505 \\
\hline Refractive astigmatism (D) & $1.85 \pm 1.07(0.87$ to 3.50$)$ & $1.84 \pm 0.81(0.75$ to 3.50$)$ & 0.723 \\
\hline
\end{tabular}

Values are presented as mean \pm standard deviation (range) or number

$\mathrm{D}=$ diopters; $\mathrm{AK}=$ arcuate keratotomy; $\mathrm{IOL}=$ intraocular lens; $\mathrm{ATR}=$ against-the-rule; WTR = with-the-rule; UDVA = uncorrected distance visual acuity; CDVA = corrected distance visual acuity; logMAR = logarithm of the minimum angle of resolution

${ }^{a}$ Differences of categorical variables assessed by Pearson's chi-square test; continuous variables assessed by Mann-Whitney $U$ test 
Table 2 Results of corneal astigmatism and refractive astigmatism

\begin{tabular}{|c|c|c|c|c|c|}
\hline & AK group & $P^{a}$ & toric IOL group & $P^{a}$ & $P^{b}$ \\
\hline \multicolumn{6}{|c|}{ Manifest refractive astigmatism (D) } \\
\hline Baseline & $1.85 \pm 1.07$ & & $1.84 \pm 0.81$ & & 0.723 \\
\hline 1-month postop & $0.96 \pm 0.37$ & & $0.62 \pm 0.32$ & & 0.024 \\
\hline 3-month postop & $0.76 \pm 0.42$ & & $0.67 \pm 0.34$ & & 0.483 \\
\hline 6-month postop & $0.99 \pm 0.51$ & & $0.68 \pm 0.21$ & & 0.057 \\
\hline 1-month vs baseline & & 0.001 & & 0.001 & \\
\hline 3-month vs baseline & & 0.000 & & 0.001 & \\
\hline 6-month vs baseline & & 0.028 & & 0.001 & \\
\hline \multicolumn{6}{|c|}{ Corneal astigmatism from automated keratometer (D) } \\
\hline Baseline & $1.44 \pm 0.39$ & & $1.50 \pm 0.37$ & & 0.505 \\
\hline 1-month postop & $0.91 \pm 0.37$ & & $1.22 \pm 0.47$ & & 0.045 \\
\hline 3-month postop & $0.99 \pm 0.67$ & & $1.35 \pm 0.33$ & & 0.021 \\
\hline 6-month postop & $0.98 \pm 0.69$ & & $1.37 \pm 0.41$ & & 0.032 \\
\hline 1-month vs baseline & & 0.001 & & 0.114 & \\
\hline 3-month vs baseline & & 0.009 & & 0.306 & \\
\hline 6-month vs baseline & & 0.013 & & $>0.999$ & \\
\hline \multicolumn{6}{|c|}{ Corneal astigmatism from topography (D) } \\
\hline Baseline & $1.49 \pm 0.36$ & & $1.60 \pm 0.47$ & & 0.235 \\
\hline 1-month postop & $0.93 \pm 0.44$ & & $1.40 \pm 0.50$ & & 0.011 \\
\hline 3-month postop & $1.02 \pm 0.52$ & & $1.50 \pm 0.47$ & & 0.010 \\
\hline 6-month postop & $0.94 \pm 0.40$ & & $1.53 \pm 0.46$ & & 0.018 \\
\hline 1-month vs baseline & & $<0.001$ & & 0.048 & \\
\hline 3-month vs baseline & & 0.003 & & 0.058 & \\
\hline 6-month vs baseline & & 0.010 & & 0.149 & \\
\hline
\end{tabular}

Values are presented as mean \pm standard deviation

$\mathrm{D}=$ diopters; $\mathrm{AK}=$ arcuate keratotomy; $\mathrm{IOL}=$ intraocular lens

${ }^{a}$ Comparison with baseline within groups assessed by Wilcoxon signed-rank test

${ }^{b}$ Comparison between groups assessed by Mann-Whitney $U$ test

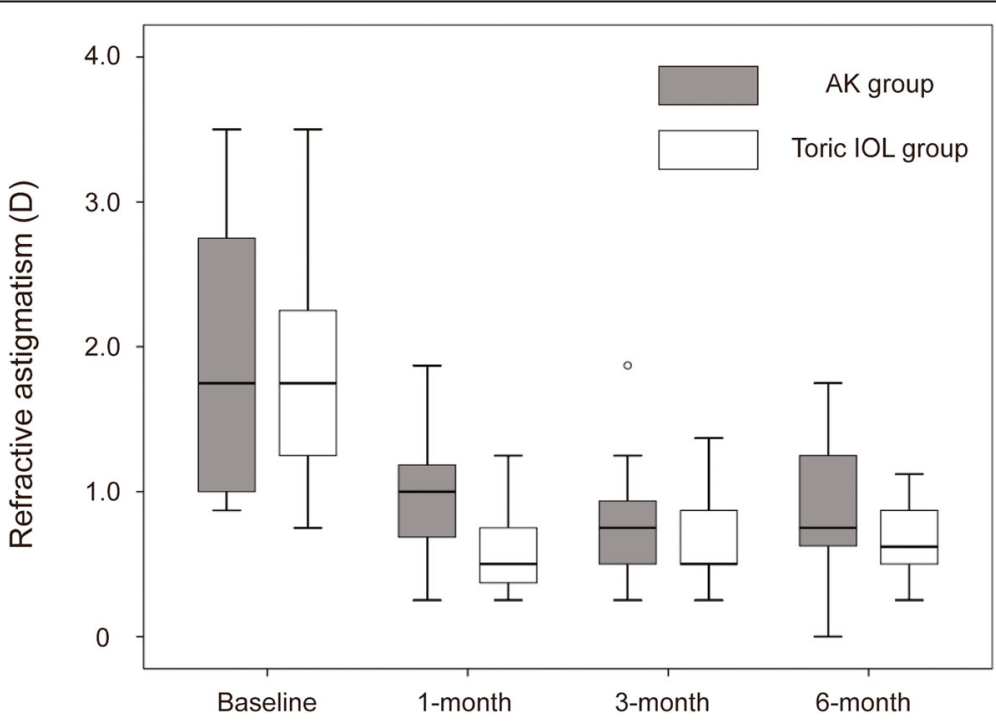

Fig. 1 Box-whisker plots of refractive astigmatism by group and time 
Table $\mathbf{3}$ Vector analysis of refractive astigmatism

\begin{tabular}{|c|c|c|c|c|c|}
\hline & AK group & $P^{a}$ & toric IOL group & $P^{a}$ & $P^{b}$ \\
\hline \multicolumn{6}{|c|}{ Surgically induced refractive correction (D) } \\
\hline 1-month postop & $1.49 \pm 1.12$ & & $1.69 \pm 0.84$ & & 0.211 \\
\hline 3-month postop & $1.57 \pm 1.51$ & & $1.49 \pm 0.75$ & & 0.465 \\
\hline 6-month postop & $1.36 \pm 0.93$ & & $1.40 \pm 0.87$ & & 0.973 \\
\hline 1-month vs 3-month & & 0.884 & & 0.006 & \\
\hline 3-month vs 6-month & & 0.794 & & 0.807 & \\
\hline 1-month vs 6-month & & 0.401 & & 0.009 & \\
\hline & & Error & & & \\
\hline 1-month postop & $0.66 \pm 0.44$ & & $0.31 \pm 0.21$ & & 0.011 \\
\hline 3-month postop & $0.60 \pm 0.44$ & & $0.37 \pm 0.10$ & & 0.071 \\
\hline 6-month postop & $0.69 \pm 0.58$ & & $0.39 \pm 0.30$ & & 0.105 \\
\hline 1-month vs 3-month & & 0.469 & & 0.552 & \\
\hline 3-month vs 6-month & & 0.222 & & 0.965 & \\
\hline 1-month vs 6-month & & 0.463 & & 0.414 & \\
\hline \multicolumn{6}{|l|}{ Correction ratio } \\
\hline 1-month postop & $0.80 \pm 0.40$ & & $0.99 \pm 0.25$ & & 0.108 \\
\hline 3-month postop & $0.82 \pm 0.54$ & & $0.81 \pm 0.23$ & & 0.465 \\
\hline 6-month postop & $0.78 \pm 0.43$ & & $0.78 \pm 0.32$ & & 0.840 \\
\hline 1-month vs 3-month & & 0.931 & & 0.004 & \\
\hline 3-month vs 6-month & & 0.809 & & 0.650 & \\
\hline 1-month vs 6-month & & 0.681 & & 0.013 & \\
\hline \multicolumn{6}{|l|}{ Error of magnitude (D) } \\
\hline 1-month postop & $0.31 \pm 0.62$ & & $0.05 \pm 0.55$ & & 0.194 \\
\hline 3-month postop & $0.24 \pm 1.18$ & & $0.34 \pm 0.51$ & & 0.808 \\
\hline 6-month postop & $0.47 \pm 0.70$ & & $0.44 \pm 0.69$ & & 0.813 \\
\hline 1-month vs 3-month & & 0.884 & & 0.006 & \\
\hline 3-month vs 6-month & & 0.794 & & 0.807 & \\
\hline 1-month vs 6-month & & 0.401 & & 0.009 & \\
\hline \multicolumn{6}{|l|}{ Error of angle $\left(^{\circ}\right)$} \\
\hline 1-month postop & $15.13 \pm 67.82$ & & $7.01 \pm 75.03$ & & 0.820 \\
\hline 3-month postop & $-0.03 \pm 75.59$ & & $-4.42 \pm 82.27$ & & 0.697 \\
\hline 6-month postop & $6.00 \pm 65.83$ & & $-12.96 \pm 74.47$ & & 0.522 \\
\hline 1-month vs 3-month & & 0.426 & & 0.594 & \\
\hline 3-month vs 6-month & & 0.968 & & 0.650 & \\
\hline 1-month vs 6-month & & 0.575 & & 0.221 & \\
\hline
\end{tabular}

Values are presented as mean \pm standard deviation

$\mathrm{D}=$ diopters; $\mathrm{AK}=$ arcuate keratotomy; $\mathrm{IOL}=$ intraocular lens

${ }^{a}$ Comparison between follow-up period within groups assessed by Wilcoxon signed-rank test

${ }^{b}$ Comparison between groups assessed by Mann-Whitney $U$ test

5). Effective postoperative astigmatism reduction was observed in all of the double-angle plots.

There was no intraoperative complication requiring secondary operation in both groups. In the AK group, no case of corneal ectasia or corneal perforation was occurred. There was no instance of IOL misalignment more than $10^{\circ}$ in the toric IOL group.

\section{Discussion}

Cataract surgery has evolved into a refractive procedure during which spherical and cylindrical errors are minimized, finally resulting in satisfactory spectacle-free visual outcomes. However, accurate surgical planning and perfect correction of astigmatism have been challenging for cataract surgeons. Many previous studies compared 


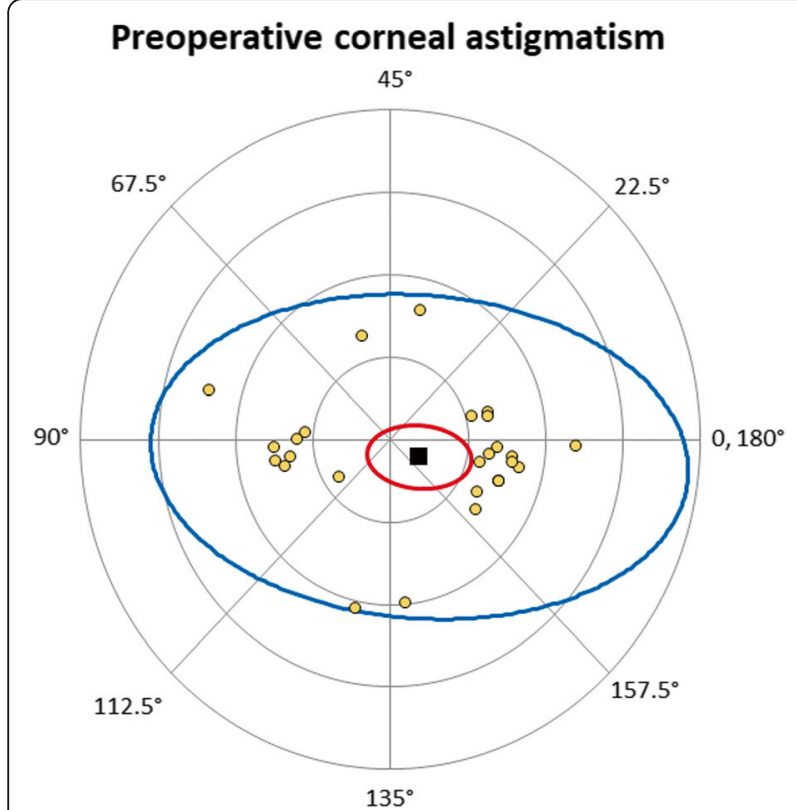

Centroid : 0.43D @ 165 $\pm 1.50 D$

Mean Absolute: $\quad 1.49 D \pm 0.36 D$

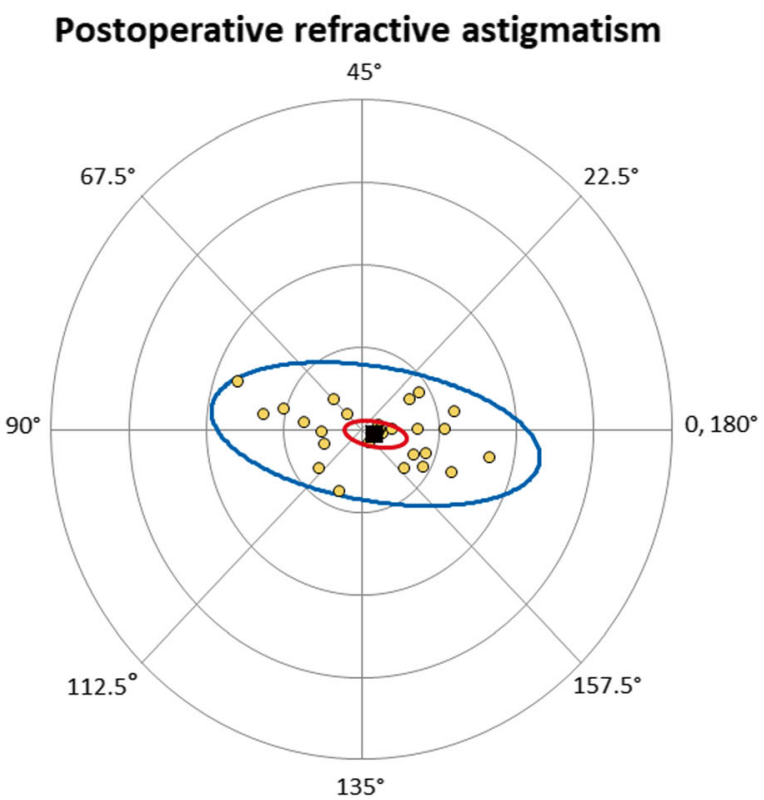

Centroid : 0.19D @ $172^{\circ} \pm 0.86 \mathrm{D}$

Mean Absolute: $\quad 0.76 D \pm 0.42 D$
$\mathrm{N}=27$

Centroid

$95 \%$ confidence ellipse of the centroid

$95 \%$ confidence ellipse of the dataset

Each ring $=1.00 \mathrm{D}$

Fig. 2 Double-angle plots of preoperative corneal astigmatism and 3-month postoperative refractive astigmatism in patients who underwent femtosecond laser-assisted cataract surgery with intrastromal arcuate keratotomy

several options during cataract surgery to correct astigmatism, including opposite clear corneal incisions, limbal relaxing incisions, manual $\mathrm{AK}$, and toric $\mathrm{IOL}$ implantation. The implantation of toric IOL is considered as an effective surgical option to reduce refractive astigmatism [14, 26, 27]. Additionally, FLACS showed comparable results with conventional cataract surgery [28]. Furthermore, simultaneous astigmatism correction with FLACS with ISAK is reported to be adjustable for managing astigmatism in cataract surgery [29]. We previously reported a comparison between femtosecond laser-assisted trans-epithelial AK after cataract surgery for residual astigmatism and cataract surgery with toric IOL implantation [19]. To the best of our knowledge, no comparison between FLACS with ISAK and toric IOL implantation in the aspect of astigmatism correction was reported yet. In the present study, we aim to compare the effectiveness of astigmatism reduction in cataract surgery between the two procedures: simultaneous FLACS with ISAK versus toric IOL implantation with conventional cataract surgery.

In this study, significant correction of refractive astigmatism was derived by both FLACS with ISAK and toric IOL implantation. Our previous study suggested that the femtosecond laser-assisted trans-epithelial AK following conventional cataract surgery is comparable to implantation of toric IOL in patients with preoperative astigmatism between +1.00 and $+3.00 \mathrm{D}$ [19]. However, there are some important differences between the current study and our previous study. That is, whereas femtosecond laser-assisted trans-epithelial AK was performed for patients who were not satisfied with their residual astigmatism, following conventional cataract surgery in our previous study, [19] femtosecond laser-assisted ISAK was performed simultaneously with FLACS in patients with lower preexisting astigmatism up to $+2.00 \mathrm{D}$ in the present study. In addition, ISAK was performed in this study, while trans-epithelial AK was done previously. ISAK with central $60 \%$ of total corneal thickness in depth remaining upper $20 \%$ and lower $20 \%$ without penetration could be safer than trans-epithelial AK which includes Bowman's layer incision followed by anterior stromal inflammation with epithelial hyperplasia [30]. According to our previous study, in cases of lower magnitude of preoperative astigmatism, there was comparable effect between femtosecond laser-assisted transepithelial AK and toric IOL implantation with regards to postoperative astigmatism correction. In the current study, also, comparable astigmatism correction was noted between simultaneous FLACS with ISAK versus 


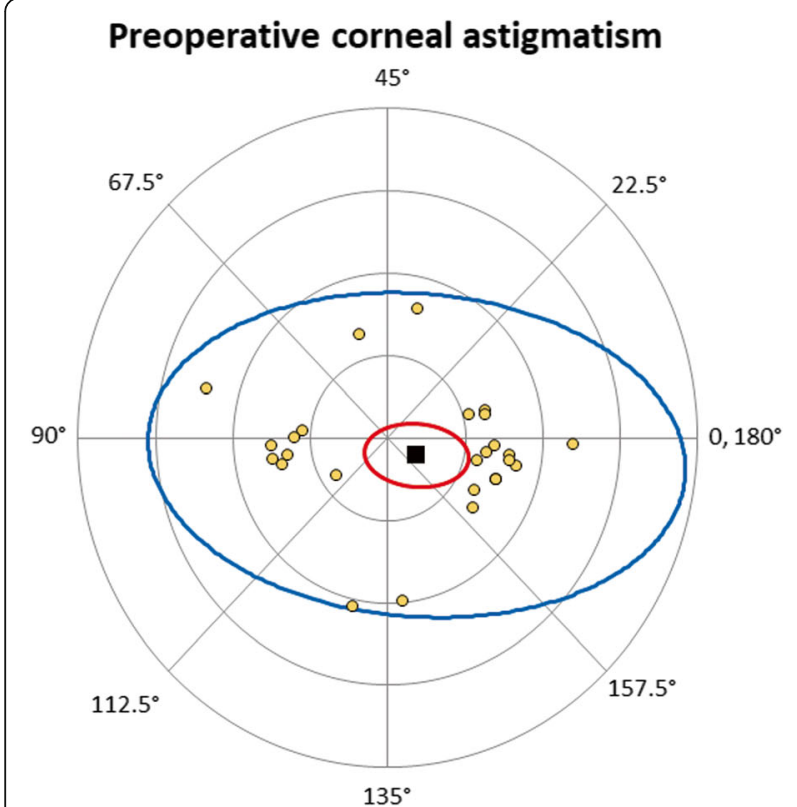

Centroid : 0.43D @ $165^{\circ} \pm 1.50 \mathrm{D}$

Mean Absolute: $\quad 1.49 D \pm 0.36 D$

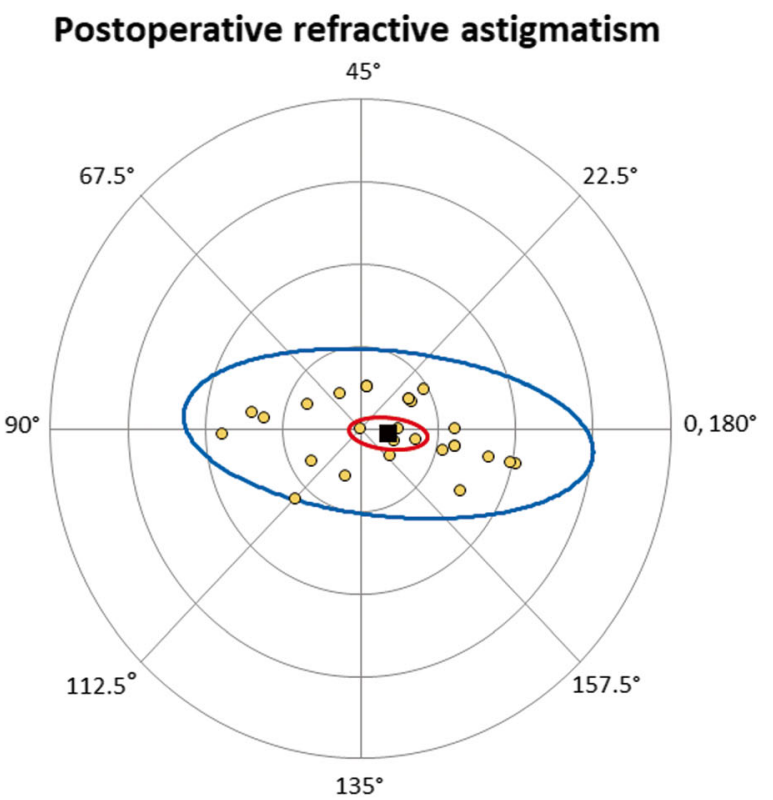

Centroid : 0.36D @ $175^{\circ} \pm 1.07 \mathrm{D}$
Mean Absolute: $\quad 0.99 D \pm 0.51 D$

$N=27$

$95 \%$ confidence ellipse of the dataset Each ring $=1.00 \mathrm{D}$

Fig. 3 Double-angle plots of preoperative corneal astigmatism and 6-month postoperative refractive astigmatism in patients who underwent femtosecond laser-assisted cataract surgery with intrastromal arcuate keratotomy

toric IOL implantation with conventional phacoemulsification in terms of refractive astigmatism reduction after cataract surgery.

By performing femtosecond laser-assisted ISAK during cataract surgery, corneal astigmatism was effectively corrected postoperatively. Significant reduction in corneal astigmatism was made in the AK group at all of each postoperative follow-up period. Principle of the toric IOL implantation does not affect corneal astigmatism. However, for the reason that on-axis clear corneal incision may alter postoperative surgically induced astigmatism in cataract surgery, corneal astigmatism as well as refractive astigmatism was also compared between the two groups. In the toric IOL group, the mean reduction of corneal astigmatism was $0.20 \mathrm{D}$ from topography and $0.32 \mathrm{D}$ from the automated keratometer at the 1-month follow-up, which dropped to $0.07 \mathrm{D}$ from topography and $0.13 \mathrm{D}$ from the automated keratometer at the 6month follow-up. These changes can be attributed to the effect of surgically induced astigmatism, and our results are consistent with results of previous studies [31, 32]. Obviously, compared to baseline preoperative levels, the amount of reduction was not significant in the toric IOL group, while significant reduction of corneal astigmatism was noted in the AK group.
The vector analysis showed better stability of astigmatism reduction in the toric IOL group compared to the AK group. In the AK group, no significant change was seen in vector analysis during each follow-up period of 1-month, 3-month, and 6-month postoperatively. In line with our results, previous study reported that the reduced corneal astigmatism after ISAK showed a stable course during 6-month postoperatively [16]. Reported stability in astigmatism correction could be attributed to the fact that femtosecond laser-assisted ISAK is performed with optical coherence tomography-guided computer software with calculated nomogram. Considering that there was no ocular complication such as corneal ectasia or epithelial ingrowth, albeit short term followup period, FLACS with ISAK can be an effective, reproducible, and precise alternative procedure not only to remove cataract, but also decrease astigmatism. Compared to the AK group, the error ratio and amount of postoperative refractive astigmatism at all follow-ups seemed to be better with smaller variability in the toric IOL group. These findings suggest better stability of astigmatic correction in toric IOL implantation with conventional cataract surgery compared to FLACS with ISAK.

Between the two groups, no significant difference was observed in the correction ratio postoperatively. These 


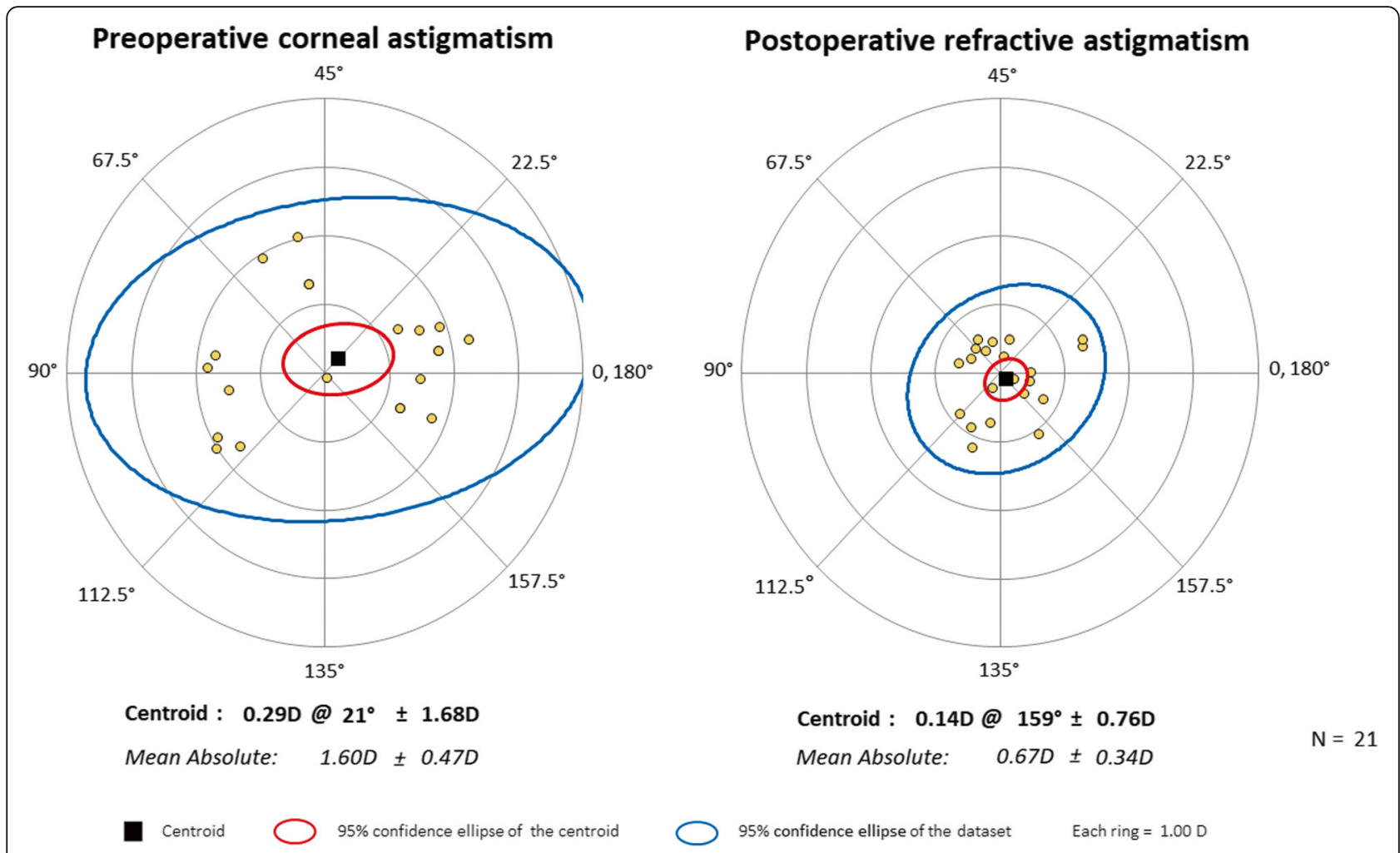

Fig. 4 Double-angle plots of preoperative corneal astigmatism and 3-month postoperative refractive astigmatism in patients who underwent cataract surgery with toric intraocular lens implantation

findings with respect to undercorrection suggest that the AK group provides comparable outcomes in astigmatic correction compared to the toric IOL group. The mean correction ratio of ISAK during FLACS in the current study was 0.82 after 3 months and 0.78 after 6 months. Byun et al. [33] previously reported a similar value of 0.72 after 3 months and 0.87 after 6 months, and Nick et al. [34] reported a mean correction ratio of 0.80 after 1 year. The current and previous studies used the same nomogram [21] of ISAK during FLACS, and these outcomes indicating undercorrection connote the need to adjust the nomogram. Rotation of IOL could also have contributed to the tendency of undercorrection in the toric IOL group. Previous studies suggest that the rotation of toric IOL contributes to the reduced correction of astigmatism $[26,35]$. Considering that $1^{\circ}$ of off-axis IOL rotation is estimated to cause a reduction of up to $3.3 \%$ of IOL cylindrical power, rotation of toric IOL is very crucial to maintain UDVA and visual quality. In our study, about $0.2 \mathrm{D}$ of cylindrical power correction was reduced from 1-month to 3-month postoperatively in the toric IOL group, which corresponds to approximately $10 \%$ of preoperative cylindrical power. Roughly $3^{\circ}$ rotation can be presumed, which corresponds to similar outcomes with the study by Miyake $\mathrm{T}$ et al. [26], which suggests a $2.2^{\circ}$ rotation 1 -week to 3 month postoperatively. Rotational stability of toric IOL should have been accounted for; however, the IOL alignment or axis was not assessed at each follow-up, which is a limitation of this study. Clinically, this minimal rotation may not significantly affect UDVA or patients' satisfaction. Nevertheless, careful routine check-up is needed in patients with toric IOL implantation.

The present study had several limitations, including its retrospective design and relatively shortterm follow-up period up to only 6 months postoperatively. Long-term results would allow a more thorough examination of corneal astigmatism changes, which could be derived from the healing response after ISAK. This study included a small sample size, making it challenging to represent definite conclusions. Despite the limited statistical power, this study represents comparable outcomes of ISAK in FLACS in terms of astigmatism correction compared to conventional cataract surgery with toric IOL implantation. A prospective randomized clinical trial study with an appropriate sample size would allow a more thorough comparison with 


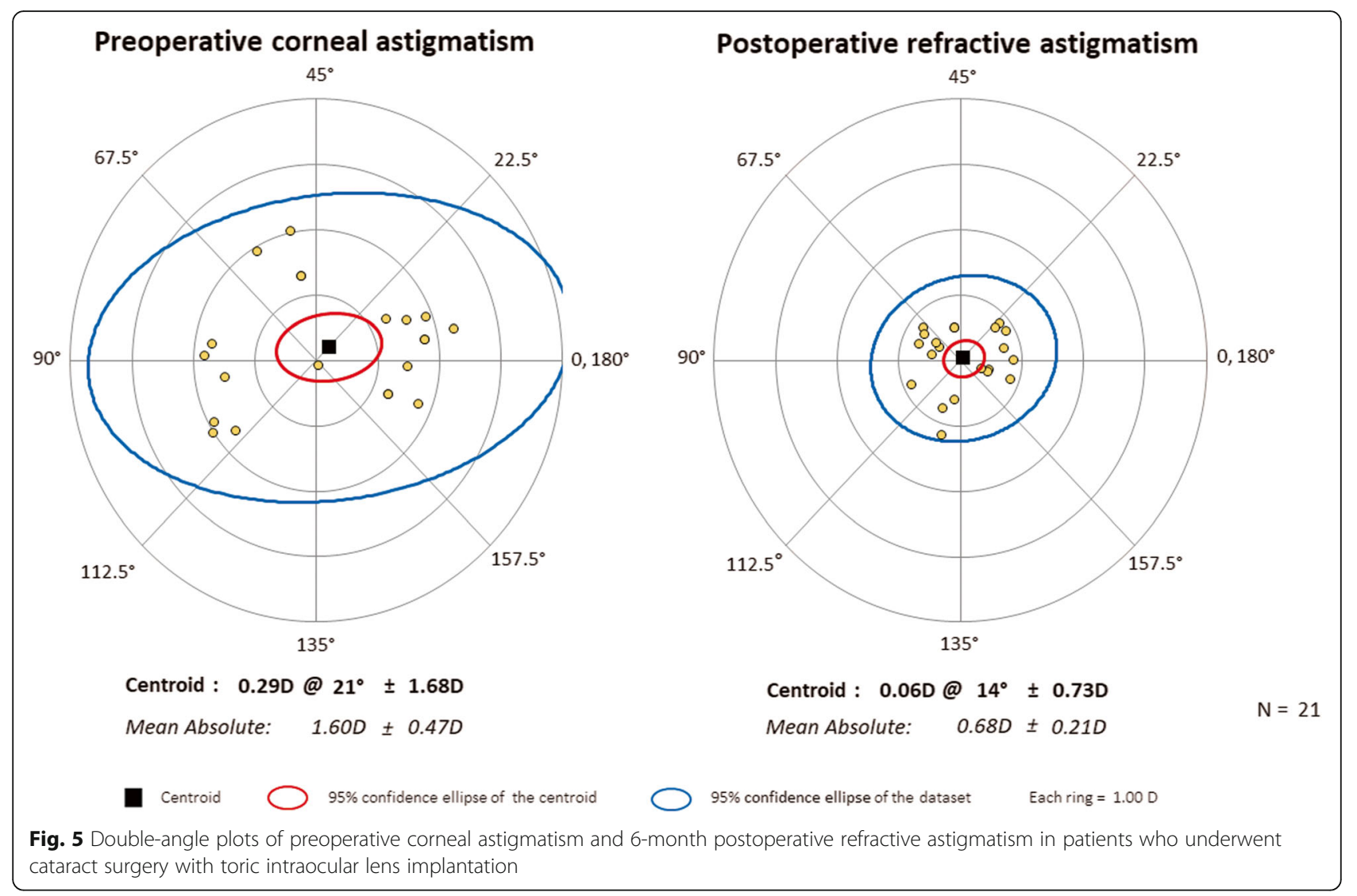

regards to astigmatism correction between the FLACS with ISAK and implantation of toric IOL during cataract surgery.

\section{Conclusions}

In conclusion, when compared with the toric IOL implantation, the ISAK in FLACS could be a comparable procedure in terms of reducing astigmatism in cataract surgery for patients with moderate astigmatism, although toric IOL implantation seems to be more stable.

\section{Abbreviations}

FLACS: Femtosecond laser-assisted cataract surgery; ISAK: Intrastromal arcuate keratotomy; AK: arcuate keratotomy; IOL: Intraocular lens; UDVA: Uncorrected distance visual acuity; CDVA: Corrected distance visual acuity

\section{Acknowledgements}

We would like to thank Editage (www.editage.co.kr) for English language editing.

\section{Authors' contributions}

Study concept and design (HJK, HL, JAL, JYK, HT); collection, management, analysis, and interpretation of data $(\mathrm{HJK}, \mathrm{HL}, \mathrm{JAL}, \mathrm{JYK}, \mathrm{HT})$; and preparation, review, or approval of the manuscript $(H J K, H L, H T)$. All authors read and approved the final manuscript.

\section{Funding}

This research was supported by Basic Science Research Program through the National Research Foundation of Korea (NRF) funded by the Ministry of
Education, Science and Technology (2020R1F1A1073627), by Research and Business Development Program through the Korea Institute for Advancement of Technology (KIAT) funded by the Ministry of Trade, Industry and Energy (MOTIE; grant number: P0014063), and by a grant from the Asan Institute for Life Sciences, Asan Medical Center, Seoul, Korea (2020IP0045-3). The funder had no role in the design and conduct of the study; collection, management, analysis, and interpretation of the data; preparation, review, or approval of the manuscript; and decision to submit the manuscript for publication.

\section{Availability of data and materials}

Data are available upon reasonable request from the authors.

\section{Declarations}

\section{Ethics approval and consent to participate}

This study was conducted with the approval of the Institutional Review Board of the Asan Medical Center and the University of Ulsan College of Medicine, Seoul, South Korea (2019-1244). The need for the written informed consent was waived because of the retrospective nature of this study.

\section{Consent for publication} Not applicable.

\section{Competing interests}

The authors have no proprietary or financial interest in the materials presented herein. 
Received: 13 August 2020 Accepted: 2 August 2021 Published online: 14 August 2021

\section{References}

1. Hoffmann PC, Hutz WW. Analysis of biometry and prevalence data for corneal astigmatism in 23,239 eyes. J Cataract Refract Surg. 2010;36(9):147985. https://doi.org/10.1016/j.jcrs.2010.02.025.

2. Hoffer KJ. Biometry of 7,500 cataractous eyes. Am J Ophthalmol. 1980;90(3): 360-8. https://doi.org/10.1016/S0002-9394(14)74917-7.

3. Khan Ml, Muhtaseb M. Prevalence of corneal astigmatism in patients having routine cataract surgery at a teaching hospital in the United Kingdom. J Cataract Refract Surg. 2011;37(10):1751-5. https://doi.org/10.1016/j.jcrs.2011. 04.026 .

4. Ferrer-Blasco T, Montes-Mico R, Peixoto-de-Matos SC, Gonzalez-Meijome JM, Cervino A. Prevalence of corneal astigmatism before cataract surgery. J Cataract Refract Surg. 2009;35(1):70-5. https://doi.org/10.1016/j.jcrs.2008.09. 027.

5. Chen W, Zuo C, Chen C, Su J, Luo L, Congdon N, et al. Prevalence of corneal astigmatism before cataract surgery in Chinese patients. J Cataract Refract Surg. 2013;39(2):188-92. https://doi.org/10.1016/j.jcrs.2012.08.060.

6. Lekhanont K, Wuthisiri W, Chatchaipun P, Vongthongsri A. Prevalence of corneal astigmatism in cataract surgery candidates in Bangkok, Thailand. J Cataract Refract Surg. 2011;37(3):613-5. https://doi.org/10.1016/j.jcrs.2010.12. 038.

7. Visser N, Bauer NJ, Nuijts RM. Residual astigmatism following toric intraocular lens implantation related to pupil size. J Refract Surg. 2012 28(10):729-32. https://doi.org/10.3928/1081597X-20120911-02.

8. Wolffsohn JS, Bhogal G, Shah S. Effect of uncorrected astigmatism on vision. J Cataract Refract Surg. 2011;37(3):454-60. https://doi.org/10.1016/j.jcrs.2010. 09.022.

9. Behndig A, Montan P, Stenevi U, Kugelberg M, Zetterstrom C, Lundstrom M. Aiming for emmetropia after cataract surgery: Swedish National Cataract Register study. J Cataract Refract Surg. 2012;38(7):1181-6. https://doi.org/1 0.1016/j.jcrs.2012.02.035.

10. Lee H, Kim TI, Kim EK. Corneal astigmatism analysis for toric intraocular lens implantation: precise measurements for perfect correction. Curr Opin Ophthalmol. 2015;26(1):34-8. https://doi.org/10.1097/ICU.0000000000000119.

11. Fouda S, Kamiya K, Aizawa D, Shimizu K. Limbal relaxing incision during cataract extraction versus photoastigmatic keratectomy after cataract extraction in controlling pre-existing corneal astigmatism. Graefes Arch Clin Exp Ophthalmol. 2010;248(7):1029-35. https://doi.org/10.1007/s00417-009-12 72-6.

12. Bayramlar H, Daglioglu MC, Borazan M. Limbal relaxing incisions for primary mixed astigmatism and mixed astigmatism after cataract surgery. J Cataract Refract Surg. 2003;29(4):723-8. https://doi.org/10.1016/S0886-3350(02)018217.

13. Kamiya K, Umeda K, Ando W, Igarashi A, Shimizu K. Clinical outcomes of photoastigmatic refractive keratectomy for the correction of residual refractive errors following cataract surgery. J Refract Surg. 2011;27(11):82631. https://doi.org/10.3928/1081597X-20110623-02.

14. Kessel L, Andresen J, Tendal B, Erngaard D, Flesner P, Hjortdal J. Toric intraocular lenses in the correction of astigmatism during cataract surgery: a systematic review and Meta-analysis. Ophthalmology. 2016;123(2):275-86. https://doi.org/10.1016/j.ophtha.2015.10.002.

15. Hayashi K, Kondo H, Yoshida M, Manabe S, Hirata A. Higher-order aberrations and visual function in pseudophakic eyes with a toric intraocular lens. J Cataract Refract Surg. 2012;38(7):1156-65. https://doi.org/1 0.1016/j.jcrs.2012.02.032.

16. Ruckl T, Dexl AK, Bachernegg A, Reischl V, Riha W, Ruckhofer J, et al. Femtosecond laser-assisted intrastromal arcuate keratotomy to reduce corneal astigmatism. J Cataract Refract Surg. 2013;39(4):528-38. https://doi. org/10.1016/j.jcrs.2012.10.043

17. Nubile M, Carpineto P, Lanzini M, Calienno R, Agnifili L, Ciancaglini M, et al. Femtosecond laser arcuate keratotomy for the correction of high astigmatism after keratoplasty. Ophthalmology. 2009;116(6):1083-92. https:// doi.org/10.1016/j.ophtha.2009.01.013.

18. Wetterstrand O, Holopainen JM, Krootila K. Treatment of postoperative keratoplasty astigmatism using femtosecond laser-assisted intrastromal relaxing incisions. J Refract Surg. 2013;29(6):378-82. https://doi.org/10.3928/1 081597X-20130515-01.
19. Yoo A, Yun S, Kim JY, Kim MJ, Tchah H. Femtosecond laser-assisted arcuate keratotomy versus Toric IOL implantation for correcting astigmatism. J Refract Surg. 2015;31(9):574-8. https://doi.org/10.3928/1081597X-2015082001.

20. Nejima R, Terada Y, Mori Y, Ogata M, Minami K, Miyata K. Clinical utility of femtosecond laser-assisted astigmatic keratotomy after cataract surgery. Jpn J Ophthalmol. 2015;59(4):209-15. https://doi.org/10.1007/s10384-015-0383-3.

21. Day AC, Lau NM, Stevens JD. Nonpenetrating femtosecond laser intrastromal astigmatic keratotomy in eyes having cataract surgery. J Cataract Refract Surg. 2016;42(1):102-9. https://doi.org/10.1016/j.jcrs.2015.07. 045.

22. Chan TC, Cheng GP, Wang Z, Tham CC, Woo VC, Jhanji V. Vector analysis of corneal astigmatism after combined femtosecond-assisted phacoemulsification and arcuate keratotomy. Am J Ophthalmol. 2015;160(2): 250-5 e252. https://doi.org/10.1016/.ajo.2015.05.004.

23. Eydelman MB, Drum B, Holladay J, Hilmantel G, Kezirian G, Durrie D, et al. Standardized analyses of correction of astigmatism by laser systems that reshape the cornea. J Refract Surg. 2006;22(1):81-95. https://doi.org/10.392 8/1081-597X-20060101-16.

24. Reinstein DZ, Archer TJ, Randleman JB. JRS standard for reporting astigmatism outcomes of refractive surgery. J Refract Surg. 2014;30(10):6549. https://doi.org/10.3928/1081597X-20140903-01.

25. Dupps WJ Jr, Kohnen T, Mamalis N, Rosen ES, Srinivasan S, Koch DD, et al. The journal of Cataract \& Refractive Surgery: 2018 in review. J Cataract Refract Surg. 2018;44(12):1411-2. https://doi.org/10.1016/j.jcrs.2018.11.001.

26. Miyake T, Kamiya K, Amano R, lida Y, Tsunehiro S, Shimizu K. Long-term clinical outcomes of toric intraocular lens implantation in cataract cases with preexisting astigmatism. J Cataract Refract Surg. 2014;40(10):1654-60. https://doi.org/10.1016/j.jcrs.2014.01.044.

27. Roberts TV, Sharwood P, Hodge C, Roberts K, Sutton G. Comparison of Toric intraocular lenses and arcuate corneal relaxing incisions to correct moderate to high astigmatism in cataract surgery. Asia Pac J Ophthalmol (Phila). 2014;3(1):9-16. https://doi.org/10.1097/APO.0b013e3182a0af21.

28. Chan TC, Ng AL, Cheng GP, Wang Z, Woo VC, Jhanji V. Corneal astigmatism and aberrations after combined femtosecond-assisted phacoemulsification and arcuate keratotomy: two-year results. Am J Ophthalmol. 2016;170:83-90. https://doi.org/10.1016/j.ajo.2016.07.022

29. Wang J, Zhao J, Xu J, Zhang J. Evaluation of the effectiveness of combined femtosecond laser-assisted cataract surgery and femtosecond laser astigmatic keratotomy in improving post-operative visual outcomes. BMC Ophthalmol. 2018;18(1):161. https://doi.org/10.1186/s12886-018-0823-1.

30. Gray B, Binder PS, Huang LC, Hill J, Salvador-Silva M, Gwon A. Penetrating and intrastromal corneal arcuate incisions in rabbit and human cadaver eyes: manual diamond blade and femtosecond laser-created incisions. Eye Contact Lens. 2016;42(4):267-73. https://doi.org/10.1097/ICL. 0000000000000204

31. Masket S, Wang L, Belani S. Induced astigmatism with 2.2- and 3.0-mm coaxial phacoemulsification incisions. J Refract Surg. 2009;25(1):21-4. https:// doi.org/10.3928/1081597X-20090101-04.

32. Villegas EA, Alcón E, Rubio E, Marín JM, Artal P. One-year follow-up of changes in refraction and aberrations induced by corneal incision. PLoS One. 2019:14(11):e0224823. https://doi.org/10.1371/journal.pone.0224823.

33. Byun YS, Kim S, Lazo MZ, Choi MH, Kang MJ, Lee JH, et al. Astigmatic correction by intrastromal astigmatic keratotomy during femtosecond laserassisted cataract surgery: factors in outcomes. J Cataract Refract Surg. 2018; 44(2):202-8. https://doi.org/10.1016/j.jcrs.2017.11.018.

34. Stanojcic N, Roberts HW, Wagh VK, Li JO, Naderi K, O'Brart DP. A randomised controlled trial comparing femtosecond laser-assisted cataract surgery versus conventional phacoemulsification surgery: 12-month results. Br J Ophthalmol. 2021;105(5):631-8

35. Li S, Li X, He S, Zheng Q, Chen X, Wu X, et al. Early postoperative rotational stability and its related factors of a single-piece acrylic toric intraocular lens. Eye (Lond). 2020;34(3):474-9. https://doi.org/10.1038/s41433-019-0521-0.

\section{Publisher's Note}

Springer Nature remains neutral with regard to jurisdictional claims in published maps and institutional affiliations. 